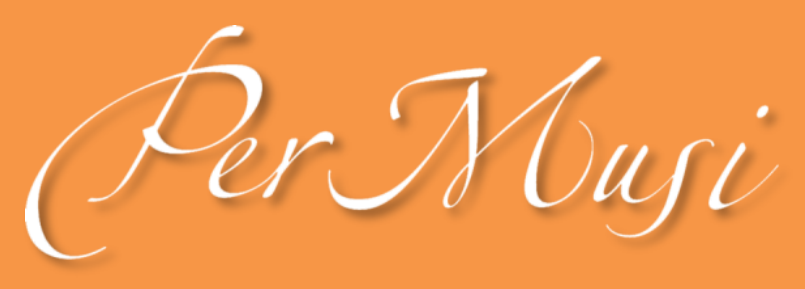

eISSN 2317-6377

\title{
Estudo populacional com regentes brasileiros sobre sua ocupação e a relação com aspectos de saúde
}

\author{
Jorge Augusto Mendes Geraldo \\ https://orcid.org/0000-0002-1812-8163 \\ Universidade Federal de Mato Grosso do Sul, Faculdade de Artes, Letras e Comunicação \\ jorge.geraldo@gmail.com \\ Carlos Fernando Fiorini \\ https://orcid.org/0000-0003-0965-9744 \\ Universidade Estadual de Campinas, Instituto de Artes, Departamento de Música \\ fiorini.carlos@gmail.com
}

SCIENTIFIC ARTICLE

Submitted date: 11 mar 2020

Final approval date: 11 may 2021

Resumo: Este texto apresenta resultados de um estudo seccional com regentes brasileiros em atividade. Realizou-se uma coleta de dados on-line, por meio de um questionário e de instrumentos de avaliação autoaplicáveis, com o intuito de investigar a formação, o trabalho e o impacto na saúde da atividade de regência dos participantes. Os resultados indicam uma insatisfação com os locais de atividades utilizados e uma percepção de impacto negativo no trabalho pelos regentes quanto ao aspecto psicológico, físico, vocal e auditivo. A percepção de dor associada à regência foi predominante na região dos ombros, pescoço e região dorsal e lombar, sendo que parte das queixas apresentou relação com características específicas do trabalho. Como conclusão, o estudo aponta a necessidade de uma avaliação do currículo nos cursos de regência quanto à existência de conteúdo sobre saúde e à importância de oferecer aos regentes soluções para os problemas inerentes ao trabalho.

Palavras-chave: Regência (Música); Saúde ocupacional; Doenças profissionais; Fatores de risco.

\section{TITLE: POPULATION STUDY WITH BRAZILIAN CONDUCTORS ON THEIR OCCUPATION AND ITS RELATION WITH HEALTH ASPECTS}

Abstract: This paper presents the results of a cross-sectional study of active Brazilian conductors. One carries out an online data collection through a questionnaire and self-applied assessment tools to investigate aspects of training, work, and health impact of the conducting activity of the participants. The results indicate a dissatisfaction about the places of activities and a perception of a negative impact on their work regarding the psychological, physical, vocal, and auditory aspects. The sensation of pain associated with conducting was predominant in the shoulders, neck and dorsal and lumbar regions and part of them finds an association with specific work characteristics. In conclusion, the study points out the need for an evaluation of the curriculum in conducting courses as to the existence of content on health and the importance of offering solutions to the conductors regarding the problems inherent to the work. Keywords: Conducting (Music); Occupational health; Professional disease; Risk factor. 


\section{Estudo populacional com regentes brasileiros sobre sua ocupação e a relação com aspectos de saúde}

Jorge Augusto Mendes Geraldo, Universidade Federal de Mato Grosso do Sul, jorge.geraldo@gmail.com Carlos Fernando Fiorini, Universidade Estadual de Campinas, fiorini.carlos@gmail.com

\section{Introdução}

O impacto da atividade de regência sobre a saúde foi objeto de poucos estudos dentro da literatura científica. Entretanto, as pesquisas desenvolvidas indicam riscos específicos por conta de movimentos repetitivos dos membros superiores, de exigência física em consequência da permanência na postura em pé, de exposição prolongada à intensidade sonora além dos níveis recomendados e de demasiada exigência vocal (Hayes 2013; Averill e Sedatole 2011; Rehder e Behlau 2008).

Uma revisão bibliográfica prévia encontrou apenas dois estudos populacionais com regentes brasileiros tratando de aspectos de saúde. As duas pesquisas abordavam especificamente demandas vocais e verificaram uma prevalência considerável de sintomas associados à atividade de trabalho (Gonçalves e Silvério 2009; Rehder e Behlau 2008).

Mesmo considerando a regência de forma ampla, há poucos estudos populacionais que oferecem informações sobre aspectos gerais da profissão, como a rotina de trabalho e a formação dos regentes brasileiros. Em um trabalho recente com autoria de Cibele Sabioni (2016), foram coletados dados de participantes de dois cursos de formação de regentes, um técnico e outro sazonal. Uma das considerações da autora é de que, frequentemente, coros iniciantes em determinadas regiões são dirigidos por regentes com formação específica de Licenciatura em Música.

Em função da necessidade de conhecer melhor esses profissionais em regência, seu trabalho, suas demandas e sua formação e de recolher informações relacionadas à saúde, foi proposta uma busca direta com regentes em atividade.

\section{A proposta de coleta de dados}

Foi elaborado um estudo seccional observacional, por meio de um questionário e de instrumentos de avaliação autoaplicáveis, para avaliar a prevalência das variáveis de interesse no conjunto de sujeitos avaliados. Após a coleta, os dados passaram por uma análise exploratória, utilizando recursos de estatística descritiva que auxiliaram na discussão de hipóteses sobre as informações obtidas. A proposta foi submetida à apreciação do Comitê de Ética em Pesquisa pela Plataforma Brasil, obtendo parecer favorável com registro CAE 81098017.2.0000.8142. 
Por não haver instrumentos de avaliação específicos para regentes, a coleta incluiu instrumentos de avaliação de aspectos de saúde para a população em geral, com validação no Brasil, e questões sobre a atividade dos regentes elaboradas para este estudo. As questões objetivas numéricas ou categóricas e os instrumentos de avaliação eram de preenchimento obrigatório. Também foram incluídas duas questões com formato aberto, a que os participantes puderam responder de forma opcional.

O questionário específico foi construído com perguntas sobre a formação e a rotina profissional. O objetivo foi investigar o perfil ocupacional dos sujeitos e, com isso, entender de que maneira estão estruturados sua rotina e o seu ambiente de trabalho. As questões referentes à saúde buscaram informações sobre: a percepção dos participantes sobre sua saúde no trabalho; a percepção que os participantes têm das consequências físicas que seu trabalho pode proporcionar; a possibilidade de haver conteúdos teóricos ou práticos sobre saúde contemplados no processo de aprendizado dos participantes; a procura de auxílio profissional e/ou de tratamento devido a sintomas relacionados ao trabalho de regência.

O recorte estabelecido pelos critérios de inclusão foi de regentes brasileiros com 18 anos ou mais que atuassem no Brasil com conjuntos instrumentais ou vocais e que estivessem, no momento da coleta, em atividade profissional com frequência semanal há, pelo menos, um ano. Os sujeitos foram localizados em instituições musicais que mantêm conjuntos instrumentais ou vocais, como orquestras, bandas e coros, em agrupamentos musicais de universidades, por contato com associações e organizações com coletivos de músicos e pesquisadores da área de música e por contato direto com regentes e grupos de regentes não oficiais, por meio de endereço eletrônico e mídias sociais.

O modelo de busca dos sujeitos foi diversificado por conta da dificuldade em acessar um número significativo de participantes vinculados a uma mesma instituição ou associação. Usualmente os conjuntos musicais mantêm apenas um regente, e a presença da regência dentro área de pesquisa brasileira ainda é relativamente menor que em outras modalidades musicais.

O questionário foi disponibilizado de forma on-line pela plataforma de pesquisa Survio ${ }^{\circledR 1}$. Com o link disponibilizado aos participantes, era possível acessar as informações básicas da pesquisa e o Termo de Consentimento Livre Esclarecido. Após o aceite, o participante tinha acesso ao questionário e aos instrumentos de avaliação. A pesquisa ficou disponível para preenchimento entre os dias 21 de março e 18 de setembro de 2018.

Era prevista a disponibilização do questionário em formato impresso, contudo, como o número de participantes foi satisfatório com o formato on-line, para economia de custos com deslocamento e fotocópias, optou-se pela não disponibilização impressa. O formato on-line na plataforma Survio ${ }^{\circledR}$ contribuiu para que os participantes pudessem escolher, de forma individual, o momento mais adequado para o preenchimento do questionário sem limite de tempo para completá-lo.

No texto que se segue, são apresentados: parte dos resultados da coleta sobre o perfil dos participantes; aspectos de sua formação e de sua atuação como regente e sua percepção sobre questões de saúde no trabalho. A análise consistiu em uma avaliação da frequência e centralidade das variáveis investigadas e de

\footnotetext{
${ }^{1}$ A plataforma Survio ${ }^{\circledR}$ consiste de um site on-line que hospeda pesquisas de diversas áreas, sendo utilizada por empresas privadas de reconhecimento. A plataforma disponibiliza formatos diversos de pesquisa com opções de lógica e formatação de conteúdo, o que contribuiu para um bom formato on-line para o estudo aqui descrito (https://www.survio.com/br).
} 
testes bivariados para detectar relacionamento entre características específicas. Foram conduzidos diferentes testes, dependendo do comportamento das variáveis, e as relações apontadas levaram em consideração um nível de significância de 0,05. A análise permitiu o levantamento de hipóteses sobre a atuação dos regentes e a verificação da concordância dos resultados com a literatura científica nacional e internacional da área.

\section{Discussão dos resultados}

\subsection{Dados gerais e perfil dos participantes}

Foram coletadas 178 respostas, com tempo de preenchimento médio de 30 a 60 minutos. Das respostas coletadas, 12 foram excluídas por problemas com a identificação do participante, no caso de regentes que não atentaram para os critérios de inclusão e preenchimento duplo, sendo considerada, neste caso, a resposta mais recente. O número de respostas analisadas foi de 166.

Foram coletados dados de regentes atuantes nas cinco regiões geográficas brasileiras com uma proporção de 69\% homens e 31\% mulheres, o que indica ainda uma predominância masculina na regência, similarmente a outros cargos de liderança (Hryniewicz e Vianna 2018). A Tabela 1 demonstra que metade dos participantes tinha até 40 anos de idade. A idade dos participantes aparenta uma distribuição normal com predomínio de indivíduos na faixa de 31 a 40 anos, cerca de um terço dos sujeitos.

Houve maior participação de regentes do Sudeste e Centro Oeste, seguida da região Sul, o que pode ser explicado primeiramente pela densidade populacional, mas também por conta de os centros envolvidos com o desenvolvimento da pesquisa estarem sediados em Campinas - SP e Campo Grande - MS. Este fato pode ter colaborado para uma maior concentração da coleta nas regiões Sudeste e Centro-Oeste, e não por haver necessariamente um número absoluto ou relativo maior de regentes.

Tabela 1 - Perfil dos participantes.

\begin{tabular}{|c|c|c|c|}
\hline Característica & $\mathbf{N}$ & $\%$ & $\%$ асu \\
\hline \multicolumn{4}{|l|}{ Sexo } \\
\hline Masculino & 114 & 68,67 & 68,67 \\
\hline Feminino & 52 & 31,33 & 100,00 \\
\hline \multicolumn{4}{|l|}{ Idade } \\
\hline 20 a 30 anos & 25 & 15,06 & 15,06 \\
\hline 31 a 40 anos & 58 & 34,94 & 50,00 \\
\hline 41 a 50 anos & 42 & 25,30 & 75,30 \\
\hline 51 a 60 anos & 32 & 19,28 & 94,58 \\
\hline mais de 60 anos & 9 & 15,06 & 100,00 \\
\hline \multicolumn{4}{|l|}{ Região } \\
\hline Sudeste & 109 & 65,66 & 65,66 \\
\hline Centro-Oeste & 25 & 15,06 & 80,72 \\
\hline Sul & 16 & 9,64 & 90,36 \\
\hline Nordeste & 9 & 5,42 & 95,78 \\
\hline Norte & 7 & 4,22 & 100,00 \\
\hline TOTAL & 166 & 100,00 & 100,00 \\
\hline
\end{tabular}

Cerca de $43 \%$ dos participantes relataram sofrer com ansiedade e $40 \%$, estresse. Outros problemas relatados com menor frequência foram insônia, por aproximadamente $20 \%$, e hipertensão, por $17 \%$. Cerca de $35 \%$ dos participantes já sofreram alguma lesão musculoesquelética, e mais da metade já realizou algum 
procedimento cirúrgico. Aproximadamente $30 \%$ dos participantes estavam em algum tipo de tratamento médico.

\subsection{Formação}

Entre os itens de formação, os participantes puderam escolher as opções de resposta sobre sua instrução como regente. Houve número elevado de indivíduos que selecionaram formação livre ou autodidata. Apesar de a questão ser de múltipla escolha, quase um terço dos participantes selecionou apenas um ou mais dos itens: formação autodidata, formação livre ou não possui formação específica em regência. No item formação livre, está incluída a participação em cursos e workshops curtos e aulas particulares.

Quanto ao aprendizado formal, houve predomínio da graduação em regência, seguida de pós-graduação em regência e, por fim, curso técnico. Esses dados são um reflexo de como o ensino formal de música brasileiro é caracterizado pela formação universitária. Há menos oferta de cursos de nível técnico em regência.

Notou-se que houve um número baixo de participantes com curso de graduação em andamento. Este dado pode indicar uma baixa oferta de vagas em cursos de graduação na modalidade de regência ou ainda que parte relevante dos graduandos em regência não esteja em atividade de trabalho contínua, não atendendo aos critérios de inclusão da pesquisa. Reforça-se essa segunda hipótese com o fato de haver poucos regentes atuando com vínculo de estágio, com ou sem remuneração, o que normalmente ocorre com profissionais em formação (ver Tabela 6).

Tabela 2 - Componentes da formação em regência dos participantes.

\begin{tabular}{lcc}
\hline Formação & $\mathbf{N}$ & \% \\
\hline Pós-graduação em regência (completa) & 43 & 25,90 \\
Pós-graduação em regência (em andamento) & 8 & 4,82 \\
Graduação em regência (completa) & 64 & 38,55 \\
Graduação em regência (em andamento) & 4 & 2,41 \\
Curso técnico em regência (completa) & 24 & 14,46 \\
Curso técnico em regência (em andamento) & 10 & 6,02 \\
Autodidata & 36 & 21,69 \\
Formação livre & 79 & 47,59 \\
Não tem formação específica & 17 & 10,24 \\
Outros & 33 & 27,37 \\
& & \\
TOTAL & 166 & 100,00 \\
\hline
\end{tabular}

A questão sobre formação ainda abriu a possibilidade para os participantes responderem a outros itens de formação em regência sem categorias pré-estabelecidas. Entre as 33 respostas para outras formações, os sujeitos citam, com frequência, outros cursos de graduação e pós-graduação em Música, principalmente relacionados à educação, a instrumento e canto e a campo teórico.

A citação desses cursos como componentes da formação em regência pode estar associada às diversas atribuições que os regentes têm (ver Tabela 7). A ocupação de regente, com frequência, abrange atividades docentes de musicalização, instrumento e canto. Sabioni (2016), citada na introdução, encontrou número relevante de coros iniciantes regidos por Licenciados.

A direção musical de um conjunto também implica a necessidade de conhecimento profundo de questões teóricas para a escolha dos programas, a elaboração das técnicas de ensaio que serão mais bem-sucedidas e a adaptação de partituras e arranjos (Watkins 2007, 8; Rocha 2004, 21). Esses componentes diversos que 
fazem parte do cotidiano dos regentes podem ter relação com a inclusão de outras formações em Música como parte da formação do regente.

Cerca de $92 \%$ dos participantes executavam ao menos um instrumento musical com regularidade e $89 \%$ executam-no para estudo ou performance semanalmente. Os instrumentos de teclado são os mais citados (34\%), em que se incluem piano, teclado e órgão, seguidos de metais, com $12 \%$, e madeiras, com $9 \%$. Houve ainda $47 \%$ dos respondentes que relataram executar mais de um instrumento de diferentes famílias. A maior parte dos participantes mantém uma rotina de estudo e execução instrumental de até 10 horas semanais (66\%), sendo que apenas $6 \%$ relataram uma intensa rotina com mais de 20 horas semanais.

Tabela 3 - Execução de instrumento musical.

\begin{tabular}{lccc}
\hline Instrumento & N & \% & \%acu \\
\hline Família & & & \\
Teclados (piano e outros) & 58 & 34,94 & 34,94 \\
Vários (diferentes famílias e/ou canto) & 47 & 28,31 & 63,31 \\
Metais & 20 & 12,05 & 75,30 \\
Madeiras & 15 & 9,04 & 84,34 \\
Cordas friccionadas & 8 & 4,82 & 89,16 \\
Cordas dedilhadas & 3 & 1,81 & 90,97 \\
Canto & 2 & 1,20 & 92,17 \\
Nenhum & 13 & 7,83 & 100,00 \\
& & & \\
Horas de estudo e execução (semanal) & & & \\
até 5h & 70 & 42,17 & 42,17 \\
5h a 10h & 41 & 24,70 & 66,87 \\
10h a 15h & 14 & 8,43 & 75,30 \\
15h a 20h & 13 & 7,83 & 83,13 \\
mais de 20h & 10 & 6,02 & 89,15 \\
0 & 18 & 10,84 & 100,00 \\
& & & \\
TOTAL & 166 & 100,00 & 100,00 \\
\hline
\end{tabular}

Os dados demostram que a execução instrumental é parte integrante da rotina dos participantes e que tocar um instrumento musical é frequentemente recomendado pela literatura de regência como parte da formação dos profissionais. O predomínio do piano é relevante e pode ser explicado pelo auxílio que oferece aos regentes para estudo individual ou pela necessidade da correpetição, no caso da regência de coros (ver Tabela 10). O aprendizado do piano é recomendado pela literatura didática de regência. Em alguns casos, há obrigatoriedade de executar este instrumento específico em provas de admissão de cursos universitários ou em disciplinas dos cursos de graduação em regência (FUVEST, 2018, 59; VUNESP, 2018, 40; Rocha 2004, 21; Watkins 2007, 8).

Também foi questionado se os sujeitos tinham alguma rotina de estudos práticos ou teóricos de regência. Mais da metade dos participantes relatou uma carga horária de até 5 horas de estudo. Apenas nove participantes relataram não manter atividades de estudo de regência. As informações sugerem a importância do estudo como componente da rotina durante todas as fases da carreira, o que aproxima ainda mais a carreira de regente das demais áreas de performance, nas quais o estudo prático e o teórico fazem parte do trabalho do profissional (Williamon 2004; Klickstein 2009).

Assim como na rotina de atletas, a atividade artística atinge excelência com o resultado de estudo, ensaio e prática profissional contínua. Esses componentes acompanham o performer por toda sua carreira. Para produzir o resultado final do trabalho, ou seja, um concerto, uma gravação, uma ópera, a maior parte do 
esforço está nos ensaios desenvolvidos em conjunto e no estudo individual de cada participante, incluindo o regente.

\subsection{O trabalho}

Cerca de $60 \%$ dos participantes tinham a regência como principal atividade profissional; $32 \%$ tinham como atividade principal outra ocupação na área de Música, como docência em nível básico e superior, instrumentista ou cantor, também atuação como arranjador ou compositor e funções na administração de instituições musicais. Os $8 \%$ restantes tinham como principal ocupação atividades sem relação com a área de Música.

Tabela 4 - Atividade profissional principal e tempo de atuação como regente.

\begin{tabular}{lccc}
\hline Atuação profissional (1) & $\mathbf{N}$ & \% & \%acu \\
\hline Área principal de atuação profissional & & & \\
Regência & 98 & 59,04 & 59,04 \\
Música (instrumento, canto, docência ou outra) & 54 & 32,53 & 91,57 \\
Outra (não relacionada à Música) & 14 & 8,43 & 100,00 \\
& & & \\
Tempo de atuação como regente & 25 & 15,06 & 15,06 \\
$\quad$ até 5 anos & 34 & 20,48 & 35,54 \\
5 a 10 anos & 58 & 34,94 & 70,48 \\
11 a 20 anos & 30 & 18,07 & 88,55 \\
21 a 30 anos & 19 & 11,45 & 100,00 \\
mais de 30 anos & & & \\
TOTAL & 166 & 100,00 & 100,00 \\
\hline
\end{tabular}

Aproximadamente $35 \%$ dos participantes tinham até 10 anos de atuação como regente, sendo que $15 \%$ estavam em início de carreira com atuação de até 5 anos. A categoria com mais participantes foi de 11 a 20 anos, com cerca de $35 \%$. Com tempo de atuação maior que 30 anos, estavam apenas $11 \%$ dos regentes.

Os participantes foram questionados sobre os conjuntos nos quais atuavam, sendo possível descrever até três grupos. Mais da metade dos sujeitos atuava em, ao menos, dois conjuntos, e cerca de $17 \%$ faziam-no em diferentes cidades.

Tabela 5 - Tipo e quantidade de conjuntos.

\begin{tabular}{lcc}
\hline Atuação profissional (2) & N & $\%$ \\
\hline Número de conjuntos em que atua como regente: & 73 & 43,98 \\
1 & 50 & 30,12 \\
2 & 43 & 25,90 \\
3 & & \\
Número de cidades em que atua como regente: & 136 & 81,93 \\
1 & 25 & 15,06 \\
2 & 5 & 3,01 \\
3 & 166 & 100,00 \\
TOTAL & & \\
Tipo de conjunto(s) em que atua & & \\
Apenas Instrumentais & 69 & 41,57 \\
Apenas Coro/Vocais & 63 & 37,95 \\
$\quad$ Diversos ou mistos & 34 & 20,48 \\
TOTAL & & \\
\hline
\end{tabular}


A Tabela 5 mostra que, aproximadamente, $41 \%$ dos participantes atuavam apenas em conjuntos instrumentais, enquanto $38 \%$ apenas em conjuntos vocais. O restante atuava em conjuntos mistos ou de diferentes naturezas. Entre os conjuntos instrumentais, houve predomínio de grupos orquestrais seguido de bandas. As mulheres atuavam predominantemente em conjuntos vocais, enquanto homens em conjuntos instrumentais.

Os vínculos de trabalho mais citados pelos regentes foram de prestação de serviço e de trabalho voluntário, o que pode evidenciar, primeiramente, relações de trabalho com pouca estabilidade, mas também com maior liberdade para o profissional. Como citado anteriormente, houve poucos participantes que citaram o exercício da regência como estágio, perto de $3 \%$ dos relatos. Os vínculos de trabalho em esferas governamentais somam aproximadamente $28 \%$ das citações.

Entre os vínculos citados na categoria "outros", os mais recorrentes eram relacionados a contratações esporádicas para prestação de serviço ou por curtos períodos de tempo. São citadas atuações em conjuntos religiosos que podem ocorrer de forma remunerada ou voluntária. Há relatos de trabalhos com remuneração sem registro formal ou por arrecadação voluntária dos membros de um coro.

Tabela 6 - Vínculos de trabalho.

\begin{tabular}{lcc}
\hline Vínculo de trabalho & $\mathbf{N}$ & $\%$ \\
\hline Prestador de serviço & 63 & 37,95 \\
Voluntário & 35 & 21,08 \\
Contrato de Trabalho/CLT & 34 & 20,48 \\
Concursado & 18 & 10,84 \\
Servidor Federal & 17 & 10,24 \\
Servidor Estadual & 16 & 9,64 \\
Servidor Municipal & 13 & 7,83 \\
Estágio não remunerado & 3 & 1,81 \\
Estágio remunerado & 2 & 1,20 \\
Outros & 25 & 15,06 \\
& & \\
TOTAL & 166 & 100,00 \\
\hline
\end{tabular}

Cerca de $80 \%$ dos regentes participavam de até 4 ensaios semanais com uma carga de até 10 horas. 0 número de apresentações foi obtido por uma extrapolação para um período de um ano das respostas oferecidas para todos os conjuntos regidos pelo participante, sendo o resultado dividido por 12 para uma estimativa mensal. Aproximadamente $65 \%$ dos sujeitos realizavam até 3 apresentações mensais.

Do total de 302 conjuntos relatados pelos participantes, em $50 \%$, aproximadamente, era realizado intervalo nos ensaios. A análise não demonstrou relação entre a duração do ensaio e a realização do intervalo. A literatura descreve que intervalos de repouso entre atividades de ensaio em conjunto são recomendados para promover o descanso físico e mental. Essas pausas devem ser mais frequentes em grandes conjuntos e quando há grande intensidade sonora no programa executado (Klickstein 2009). A coleta de dados revelou que há casos de regentes que realizam ensaios com duração de até quatro horas ininterruptas.

Foi perguntado aos sujeitos quais atividades fazem parte de suas atribuições como regente nos conjuntos em que atuavam, além do ato de reger propriamente um grupo musical. Todos os participantes do estudo

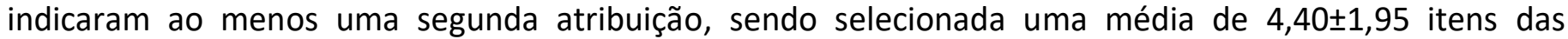
categorias pré-estabelecidas. 
O trabalho de escrita de arranjos e cópia de partituras é o mais comum e foi indicado por mais de $70 \%$ dos sujeitos. Com prevalência em torno de $60 \%$ ou mais, estão atividades de ensino e de produção e administrativas. A correpetição é indicada por cerca de $30 \%$ dos participantes, sendo que o índice ultrapassa $40 \%$ quando desconsiderados os regentes que não atuam em um conjunto vocal. Os índices altos para as atividades de ensino sustentam as respostas oferecidas pelos sujeitos na categoria "outros" sobre a formação em regência (Tabela 2), que ressaltam cursos na área de Música voltados para conteúdos teóricos, bacharelados e licenciaturas em instrumento ou canto.

Tabela 7 - Atribuições do trabalho dos regentes.

\begin{tabular}{lcc}
\hline Atividades que fazem parte do trabalho & $\mathbf{N}$ & $\%$ \\
\hline Escrita de arranjos, partituras, copista & 120 & 72,09 \\
Professor de teoria/conteúdos teóricos & 110 & 66,27 \\
Atividades de produção & 103 & 62,05 \\
Professor de instrumento ou canto & 100 & 60,24 \\
Instrumentista ou canto & 98 & 59,04 \\
Atividades administrativas & 98 & 59,04 \\
Correpetição/Piano & 49 & 29,52 \\
Outras & 29 & 17,53 \\
& & \\
TOTAL & 166 & $100,00 \%$ \\
\hline
\end{tabular}

Além das respostas oferecidas para as categorias pré-definidas, foi notável uma variedade de respostas para a categoria "outras" da Tabela 7. Foram indicadas desde direção artística, funções eminentemente de administração e de gestão, captação de recursos e elaboração de projetos, marketing, preparação vocal, até funções mais diferenciadas, como o transporte de músicos ou motorista.

Mais da metade dos participantes relatou que ao menos um dos locais utilizados para ensaio não é satisfatório, e as reclamações mais frequentes são sobre a inadequação acústica, insuficiência de espaço físico, influência de ruído externo e condições ruins de climatização. É conhecida, na literatura, a influência negativa sobre a saúde do profissional que o ambiente pode ter. No caso da regência, as condições acústicas e a influência de ruído externo podem interferir na saúde auditiva e vocal do indivíduo (Hayes 2013; Gonçalves e Silvério 2009). A falta de espaço também pode ter consequências na exposição ao ruído dos que estão no ambiente de atividades (Rodrigues et al. 2014; Hayes 2013). As condições de climatização podem ter influência sobre a voz, principalmente associadas aos níveis de umidade do ambiente, que sofre variações dependendo dos recursos utilizados (Macdonald 2004).

A inadequação dos locais pode ter relação com o tipo de ambiente utilizado para os ensaios. Menos da metade dos sujeitos relatou utilizar uma sala exclusiva para o desenvolvimento das atividades. A maior parte dos locais é compartilhada e parece não ter as especificações adequadas. A resposta mais frequente na categoria "outros" relata a utilização de igrejas e templos religiosos que podem ser satisfatórios para o ensaio de conjuntos vocais, mas insatisfatórios para grupos de sopros de grande porte, por exemplo. Os participantes que regiam apenas conjuntos instrumentais relataram mais insatisfação com as condições acústicas do que os que regiam apenas conjuntos vocais. 
Tabela 8 - Caracterização dos locais utilizados para ensaio.

\begin{tabular}{lcc}
\hline Locais de ensaio & $\mathbf{N}$ & $\%$ \\
\hline Satisfação & 90 & 54,22 \\
Ao menos um dos locais é inadequado ou necessita de adaptação & 76 & 45,78 \\
Todos os locais são satisfatórios & \\
& & \\
Quais condições do local de ensaio não são satisfatórias? & 74 & 44,58 \\
Condições acústicas ruins & 55 & 33,13 \\
Espaço insuficiente para atividades & 47 & 28,31 \\
Influência de ruído externo & 47 & 28,31 \\
Condições ruins de climatização & 32 & 19,28 \\
Falta de material para realização das atividades & 27 & 16,27 \\
Condições ruins de iluminação & 7 & 4,20 \\
Outros & & \\
& & \\
Local utilizado & 93 & 56,02 \\
Sala comum & 79 & 47,59 \\
Sala exclusiva & 38 & 22,89 \\
Sala de aula & 9 & 5,42 \\
Barracão ou Galpão & 3 & 1,81 \\
Ginásio & 11 & 6,63 \\
Estúdio & 25 & 15,06 \\
Outros & 166 & 100,00 \\
\hline TOTAL & & \\
\hline
\end{tabular}

Mais de $70 \%$ dos regentes entrevistados faziam o uso da batuta, sendo que cerca de $40 \%$ utilizam-na sempre. Quase a totalidade dos que utilizam a batuta empunham-na com a mão direita, apesar de $30 \%$ declararemse canhotos. Apenas dois regentes alternavam a mão com que empunham a batuta ainda que $28 \%$ considerassem-se ambidestros.

Tabela 9 - Uso da batuta.

\begin{tabular}{lcc}
\hline Batuta & $\mathbf{N}$ & $\%$ \\
\hline Habilidade Manual & 144 & 40,36 \\
$\quad$ Destro & 13 & 30,72 \\
Canhoto & 9 & 28,92 \\
$\quad$ Ambidestro & & \\
$\quad$ & & \\
Uso da batuta & 67 & 40,36 \\
$\quad$ Utiliza batuta sempre & 99 & 59,64 \\
$\quad$ Nunca ou eventualmente & 166 & 100,00 \\
TOTAL & & \\
Com que mão empunha? & 115 & 97,45 \\
$\quad$ Direita & 2 & 1,69 \\
$\quad$ Alterna a mão & 1 & 0,84 \\
$\quad$ Esquerda & 118 & 100,00 \\
\hline TOTAL & & \\
\hline
\end{tabular}

O uso do piano para atividades de ensaio foi relatado por cerca de $40 \%$ dos entrevistados, e $80 \%$ dos que o utilizam fazem-no ao menos por metade do tempo da atividade. Além disso, cerca de $60 \%$ dos que fazem uso do piano deixam de realizar o gestual próprio da regência para poder correpetir para o conjunto. 
Tabela 10 - Uso do piano.

\begin{tabular}{lcc}
\hline Piano & $\mathbf{N}$ & $\%$ \\
\hline Utiliza piano para ensaio & 96 & 57,83 \\
$\quad$ Não & 70 & 42,17 \\
$\quad$ Sim & 166 & 100,00 \\
TOTAL & & \\
Você utiliza o piano & & \\
$\quad$ por todo o tempo da atividade & 23 & 32,86 \\
$\quad$ mais da metade do tempo da atividade & 19 & 27,14 \\
$\quad$ metade do tempo & 13 & 18,57 \\
$\quad$ menos da metade do tempo & 5 & 7,14 \\
$\quad$ por pouco tempo & 11 & 15,71 \\
TOTAL & 70 & 100,00
\end{tabular}

Deixa de realizar o gestual de regência por conta do piano

\begin{tabular}{lcc} 
Poucas vezes & 27 & 38,57 \\
Quase metade do tempo & 14 & 20,00 \\
Quase sempre & 23 & 32,85 \\
Sempre & 6 & 8,57 \\
\hline L & 70 & 100,00
\end{tabular}

A partitura é o item de trabalho mais utilizado, com quase a totalidade dos sujeitos indicando seu uso. Em seguida, há o piano, o pódio e a lousa. Destaca-se que a maior parte dos regentes indicou o uso de um assento comum. Não é claro se esse assento tem a função de descanso ou para que o indivíduo possa executar o piano, visto que não é um assento adequado para conduzir um conjunto musical na posição sentada. Como o regente precisa ser bem visualizado pelos músicos, uma cadeira alta é a mais recomendada, sendo apontada por $40 \%$ dos participantes. Também foi relatado, de forma espontânea, o uso de equipamentos de som, órgão e teclado, batuta e diapasão.

Foram feitas três perguntas sobre o vestuário de trabalho, sendo as duas primeiras sobre os itens mais utilizados. Para os ensaios, houve maior indicação de roupas leves e menos formais como camiseta, calça jeans e tênis. Para as apresentações, há predomínio de itens como sapato social, camisa social, terno, paletó e gravata. A última pergunta sobre vestuário questionou os indivíduos sobre quais itens de vestuário podem influenciar negativamente no desempenho físico, segundo sua percepção. O item com maior indicação foi sapatos com salto alto, respondido por cerca de um terço dos participantes, em seguida, sandálias de salto alto, vestido curto, paletó e terno.

Os calçados com salto alto, sandálias e sapatos, relativamente mais apontados como prejudiciais ao desempenho físico, são utilizados com frequência por, aproximadamente, $67 \%$ das mulheres participantes do estudo. Ademais, o paletó e terno que constam entre os mais prejudiciais, indicados por mais de $20 \%$ dos participantes, têm ampla utilização em concertos. Por outro lado, os itens menos percebidos como prejudiciais, como camiseta, tênis e calça jeans, têm pouco uso em situações de concertos e apresentações.

O uso de determinados itens de vestuário no ambiente de trabalho segue convenções culturais, entretanto as limitações precisam ser avaliadas com atenção. A utilização de calçados com saltos altos é contraindicada para profissões exercidas predominantemente na posição em pé, pois oferecem menos estabilidade. Calçados com saltos altos fazem com que a musculatura postural seja mais exigida durante o trabalho (Albuquerque e Silva 2003). O paletó como item individual ou parte do terno pode limitar movimentos dos 
membros superiores que são bastante exigidos durante a regência. Os regentes devem promover ajustes conforme sua anatomia individual de forma a ter maior liberdade para executar o gestual.

Tabela 11 - Permanência em pé nos ensaios.

\begin{tabular}{lccc}
\hline Tempo de permanência em pé & $\mathbf{N}$ & $\mathbf{\%}$ & \%acu \\
\hline durante todo o ensaio & 62 & 37,35 & 37,35 \\
mais da metade do tempo & 51 & 30,72 & 68,07 \\
metade do tempo & 24 & 14,46 & 82,53 \\
por pouco tempo & 19 & 11,45 & 93,98 \\
quase não fico em pé & 10 & 6,02 & 100,00 \\
TOTAL & 166 & 100,00 & 100,00 \\
\hline
\end{tabular}

Cerca de $70 \%$ dos regentes permanecem mais da metade do tempo do ensaio em pé, sendo que $37 \%$ permanecem em pé durante toda a atividade. A permanência em pé como fator de risco ocupacional é abordada tanto na literatura de Saúde do Trabalhador, como na literatura científica e didática de regência (Geraldo e Fiorini 2017; Lopes 2016; Averil e Sedatole 2011; Rocha 2004).

\subsection{Percepção sobre a atividade de regência e saúde}

Perguntados sobre o impacto da regência em sua saúde, 70\% dos sujeitos relataram ao menos um aspecto afetado pelo trabalho. Em consonância com estudos populacionais com regentes desenvolvidos na década de 1980, a principal queixa levantada foi o impacto psicológico do trabalho, sendo esse aspecto apontado por mais da metade dos participantes (Simons 1986; Fry e Peters 1987). Os dois próximos aspectos indicados por mais de $40 \%$ dos participantes foram o físico e o vocal, sobre os quais há indicações de impacto na literatura (Averill e Sedatole 2011; Rehder e Behlau 2008; Gonçalves e Silvério 2009).

Tabela 12 - Permanência em pé.

\begin{tabular}{lcc}
\hline Influência negativa & N & \% \\
\hline Psicológico & 92 & 55,09 \\
Físico & 74 & 44,31 \\
Vocal & 72 & 43,11 \\
Nenhum & 39 & 23,35 \\
Auditivo & 30 & 17,96 \\
Cardiovascular & 16 & 9,58 \\
Visão & 15 & 8,98 \\
Outros & 9 & 5,42 \\
Não sei responder & 6 & 3,59 \\
& & \\
TOTAL & 166 & 100,00 \\
\hline
\end{tabular}

Aproximadamente $54 \%$ dos regentes indicaram mais de um dos aspectos elencados na Tabela 12 . Esse foi um dado esperado, visto que o indivíduo está exposto a diferentes fatores de risco durante o exercício de seu trabalho. Não parece ser comum que o impacto ocorra de forma a atingir a saúde em apenas um aspecto particular.

Quase a totalidade dos participantes entende que a regência exige fisicamente dos indivíduos. Essa informação encontra paralelos na literatura, por exemplo, no trabalho de Jaque et al. (2015), que avaliou dois casos em que as medidas de gasto energético apontam que a regência pode ser considerada uma atividade intensa. A literatura didática da área também ressalta a exigência física da regência e, consequentemente, a necessidade de preparo corporal (Rocha 2004; Watkins 2007). 
Perguntados quanto à prática de alongamento e aquecimento antes das atividades, $63 \%$ dos regentes relataram realizar algum procedimento. É interessante observar que cerca de $35 \%$ dos regentes que reconhecem a exigência física da atividade não realizam qualquer tipo de alongamento ou aquecimento. Uma das hipóteses é a falta de informação sobre os benefícios dos procedimentos ou de como realizá-los.

Dos entrevistados, cerca de $46 \%$ percebem alguma influência negativa de seu trabalho em seu bem-estar físico, mas apenas $29 \%$ já havia procurado ajuda de um profissional da área da Saúde para tratar de problemas associados à atividade de regência. As especialidades dos profissionais a que mais recorreram são, primeiramente, da área osteomuscular (Ortopedista, Fisioterapeuta, Massagista e outros), somando 33 citações; em seguida, profissionais com especialidades relacionadas à voz e à audição (Otorrinolaringologista e Fonoaudiólogo), com 13 citações; depois, profissionais que tratam de problemas psicológicos e neurológicos (Psicólogo, Psiquiatra e Neurologista), com 8 citações. Essas informações demonstram relação com as respostas oferecidas pelos sujeitos de quais são as áreas mais afetadas por conta do trabalho como regente - psicológico, físico, vocal - entretanto, não respectivamente na mesma ordem de prevalência das queixas.

Tabela 13 - Percepção sobre regência e saúde.

\begin{tabular}{lcc}
\hline Questão & $\mathbf{N}$ & $\%$ \\
\hline $\begin{array}{l}\text { Percebe que a atividade de regência exige fisicamente? } \\
\text { Sim }\end{array}$ & 162 & 97,59 \\
Não & 4 & 2,41 \\
& & \\
Realiza aquecimento e/ou alongamento antes das & & \\
atividades? & 105 & 63,25 \\
Sim & 61 & 36,75 \\
Não & & \\
Ambiente e atividade motora de seu trabalho como & & \\
regente têm influência negativa em seu bem-estar físico? & 10 & 6,02 \\
Muita & 67 & 40,36 \\
Pouca & 76 & 45,78 \\
Não & 13 & 7,83 \\
Não sei & 166 & 100,00 \\
\hline
\end{tabular}

Um número de 32 participantes ofereceu informações sobre diagnósticos dados pelos profissionais, sendo os principais relacionados à região dos ombros. Os quadros indicados foram de tendinite, lesão no manguito rotador, bursite, síndrome do ombro congelado e lesão por esforço repetitivo, com 11 indicações. Quatro indivíduos especificaram que o problema era no ombro direito e um deles relatou a necessidade de uma cirurgia.

Houve outras indicações menos frequentes de problemas físicos nos membros superiores, coluna e membros inferiores, como tendinite no cotovelo direito e síndrome do túnel do carpo, hérnia de disco, desgastes nas vértebras lombares ou cervicais, fadiga, artrite, varizes e Neuroma de Morton. Os problemas vocais indicados foram disfonia vocal e nódulo ou fenda na prega vocal.

Foi disponibilizada aos participantes uma questão aberta e opcional para descrever recomendações que os profissionais de saúde procurados fizeram especificamente quanto à atividade de regência. Das 29 respostas oferecidas, a maioria descreve recomendações de inclusão de rotinas de alongamento, aquecimento e 
fortalecimento muscular. Três relatos incluíram recomendações sobre alteração dos movimentos utilizados durante a regência, como diminuir o tamanho dos gestos, alterar o posicionamento dos braços, diminuir movimentos repetitivos e evitar a flexão do braço.

Tendo em vista a necessidade de o regente expressar-se gestualmente, qualquer restrição na movimentação dos membros superiores pode afetar o trabalho. Entretanto, um profissional com mais experiência pode utilizar alternativas para substituir posturas e gestos prejudiciais à saúde (Kella 1991).

Outras recomendações pontuais relatadas foram a inclusão de maiores períodos de repouso na rotina, controle do peso e alimentação, realização de audiometrias regulares, alternância postural e cuidados específicos com a voz. Apesar de estarem em menor número, todas parecem pertinentes quando avaliadas sob a perspectiva do trabalho desenvolvido pelos regentes e os dados expostos até o momento.

Mais da metade dos participantes relatou não ter obtido informações sobre saúde durante sua formação. Dos demais, um terço não soube indicar a origem das informações. Entre as fontes apontadas, houve conteúdo formal em aulas de graduação ou outro nível de formação e aquisição das informações de forma transversal, passadas pelos professores em aulas teóricas, práticas e conversas, sem fazer parte necessariamente do conteúdo curricular. Alguns regentes associaram a questão às aulas específicas de técnica vocal. Além disso, houve participantes que relataram o acesso às informações em cursos esporádicos na área da Música, workshops, palestras, entre outros, ainda em cursos específicos da área da Saúde e também de forma autodidata, mediante leitura e observação.

\subsection{Dor relacionada à atividade de regência}

Foi perguntado aos participantes especificamente se, em algum momento na carreira profissional, perceberam dores associadas à atividade de regência. O formato da questão permitia indicar regiões corporais pré-estabelecidas com a opção de responder sobre os lados esquerdo e direito, no caso dos membros superiores. Também era possível que os sujeitos relatassem a intensidade das dores com auxílio de uma Escala Visual Analógica, em um score variando de "0", ausência de dor, até "10", maior dor suportável (Fortunato et al. 2013).

Como pode ser observado no gráfico 1, houve prevalências maiores que $50 \%$ nas regiões dos ombros, dorsal, lombar e pescoço. Dores no ombro direito foram relatadas por mais de $60 \%$ dos participantes. Também houve queixas significativas para a região dos tornozelos e pés, com prevalência de aproximadamente $36 \%$. Para todas as regiões dos membros superiores - ombro, cotovelo/antebraço, punho/mão/dedos - o lado direito teve, relativamente ao esquerdo, maior prevalência.

Os resultados apontam que, para o conjunto de sujeitos investigado, as regiões corporais com maior prevalência de dor também são as que têm um score de intensidade maior. Os gráficos 2 e 3 mostram respectivamente as intensidades das regiões com maior e menor prevalência de dor. 0 número total de relatos de intensidades entre 5 e 10 foi maior para o ombro direito em $26 \%$ dos sujeitos, região lombar em $23 \%$, região dorsal em $22 \%$, ombro esquerdo $18 \%$ dos sujeitos, pescoço em $16 \%$ e tornozelos e pés em $14 \%$ dos sujeitos. 


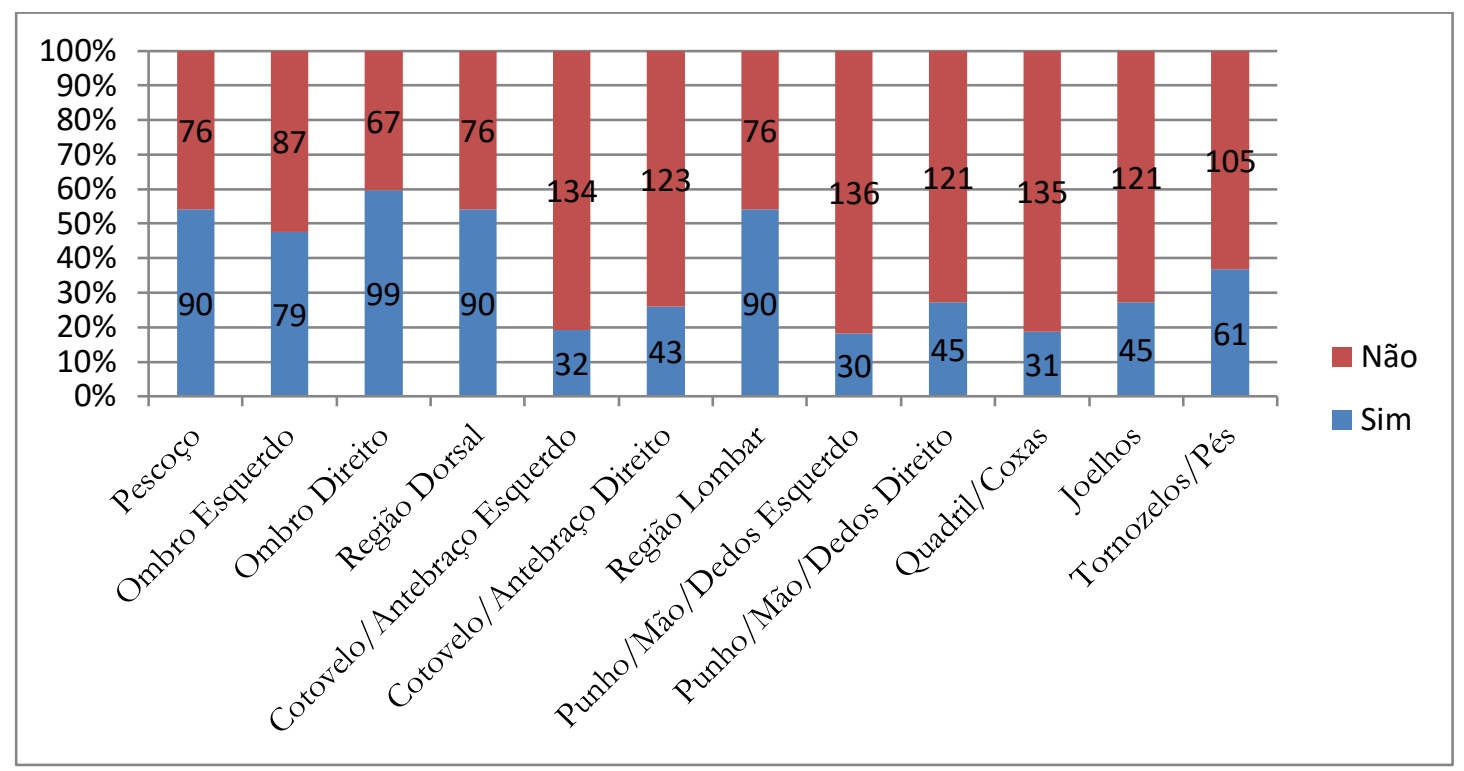

Gráfico 1 - Prevalência dos relatos de sintomas de dor associado à atividade de regência.

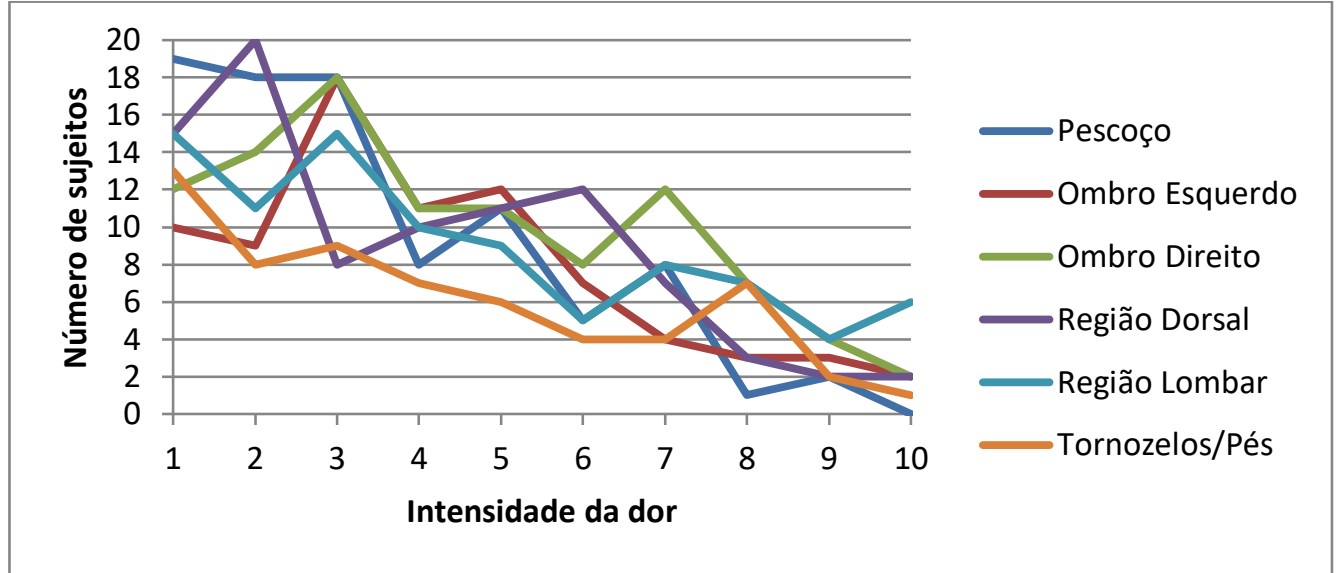

Gráfico 2 - Intensidade das regiões corporais com maior prevalência de relatos.

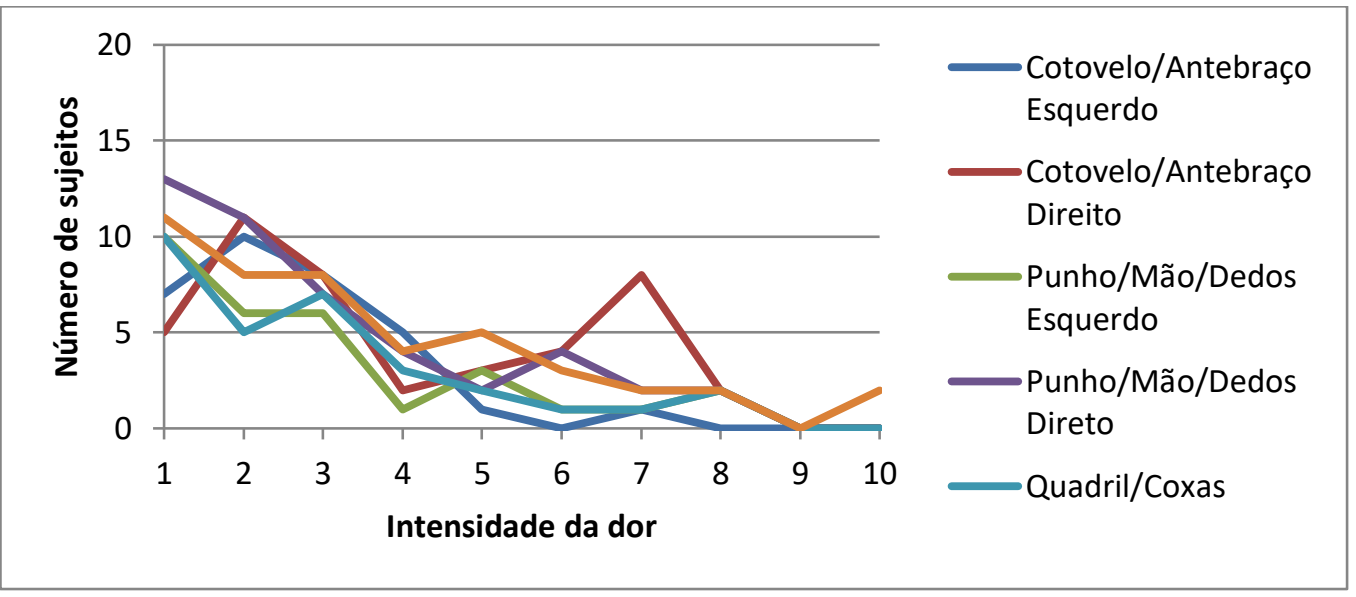

Gráfico 3 - Intensidade das regiões corporais com menor prevalência de relatos

Os resultados são similares aos oferecidos pela literatura. Evidências demonstram haver relação entre a atividade de regência e a prevalência de dores na região dos ombros, pescoço e coluna. Há, também, indicações de que o membro superior direito é mais afetado que o esquerdo (Averill e Sedatole 2011; Rose e Husain 2012; Fry e Peters 1987; Simons 1986). A própria literatura didática de regência indica que os ombros e a coluna são regiões particularmente exigidas durante o trabalho (Rocha 2004). 
A literatura também indica que um mesmo indivíduo é afetado em diferentes regiões (Fry e Peters 1987; Simons 1986). Esse aspecto foi verificado para a população estudada, sendo que aproximadamente $55 \%$ dos sujeitos relataram já ter sentido dores em quatro ou mais regiões corporais por conta da atividade de regência. Apenas $13 \%$ dos participantes indicaram não ter sentido nenhuma dor relacionada à regência.

\section{Demais considerações}

Os resultados apontam que o trabalho desenvolvido pelos participantes é difícil de ser caracterizado de forma genérica. Por haver uma quantidade considerável de variáveis envolvidas, cada indivíduo tem, além das demandas específicas da condução musical, outras relacionadas com organização do trabalho, rotina, questões administrativas e de produção.

Entre os participantes, foram encontrados regentes que atuam apenas na direção musical do conjunto, com condição de trabalho estável e funções estritamente musicais, até regentes que precisam atuar em vários conjuntos, em relações de trabalho mais instáveis e com atribuições das mais diversas, que podem inclusive afetar seu desempenho. Isso pode explicar porque cerca de $23 \%$ dos participantes relataram que a atividade de regência não os afeta na saúde. Pode haver casos em que a situação de trabalho estável e bem assistida proporcione ambientes mais favoráveis aos indivíduos bem-sucedidos na carreira. Outra possibilidade é a atuação de poucas horas como regente em trabalho comunitário. Essas atividades têm caráter mais próximo de uma atividade de lazer que profissional, o caso de alguns dos participantes.

Como verificado, também são necessários estudos aprofundados sobre a formação dos regentes de forma geral. É preciso desenvolver uma análise ampla dos conteúdos, do tipo de formação e de como o ensino de regência no Brasil está organizado. Os aspectos de saúde mostram-se pouco estruturados dentro dos cursos formais, o que reforça a análise feita por Costa (2016) quanto à saúde do músico de forma geral. A inclusão de disciplinas sobre saúde da performance em cursos superiores são, muitas vezes, iniciativas particulares de docentes e, por conta disso, não são oferecidas de forma permanente.

O conjunto de sujeitos avaliados parece sofrer impactos semelhantes aos indicados pela literatura, quando observadas as doenças indicadas, as regiões afetadas e os aspectos de saúde mais prejudicados (Geraldo e Fiorini 2017; Averill e Sedatole 2011; Gonçalves e Silvério 2009; Rehder e Behlau 2008; Kella 1991; Fry e Peters 1987; Simons 1986).

O impacto psicológico demonstrou-se o mais prevalente, por isso há necessidade de estudos aprofundados sobre este aspecto. Um dos fatores que parece ter influência nesse campo é a quantidade de tarefas, das elencadas na Tabela 7, que fazem parte do trabalho dos participantes. Houve correlação significativa entre a média do número de tarefas assumidas pelo regente e o relato de impacto negativo psicológico $\left(p-0,013^{\dagger}\right)^{2}$. A questão da polivalência do regente é recorrente na literatura, o que indica que parte do estresse da profissão pode ser influenciado por esse aspecto. Algumas das funções que o regente assume poderiam ser realizadas por profissionais especializados, como um arranjador, copista, pianista correpetidor, administrador entre outros (Gonçalves e Silvério 2009; Rocha 2004; Kella 1991).

A literatura de Saúde do Trabalhador também aponta que problemas psicológicos relacionados ao trabalho podem ter influência de condições empregatícias instáveis (Lopes 2016, 163). Como a maioria dos regentes tinha mais de um vínculo de trabalho, houve dificuldade em relacionar a influência negativa psicológica com

\footnotetext{
${ }^{2}$ Teste t para duas amostras independentes.
} 
cada vínculo separadamente. Entretanto, os participantes que selecionaram vínculo de trabalho "Concursado" relataram significativamente menor impacto psicológico negativo, com forte indicação de relacionamento entre essas características $\left(p-0,002^{*}\right)^{3}$.

Jaque et al. (2015) apontaram que o regente pode ser impactado por problemas relacionados à ansiedade na performance, que é um fator relevante em estudos já desenvolvidos com músicos. Como cerca de $40 \%$ dos participantes indicaram sofrer de ansiedade ou estresse, parece haver necessidade de estudos avaliando o impacto desse aspecto específico em regentes. Também é necessário investigar por que, mesmo com maior prevalência das queixas de impacto psicológico, a busca por profissionais especializados dessa área não ocorre em maior proporção.

O impacto físico relatado pelos participantes encontra ressonância nos índices de prevalência de dor associada à regência. A explicação está nas próprias características da regência em que predominam a permanência na posição em pé por longos períodos e a realização de movimentos repetitivos com os membros superiores (Geraldo e Fiorini 2017; Averill e Sedatole 2011; Rocha 2004; Kella 1991). Levantou-se a hipótese de que esse impacto seja potencializado por aspectos da rotina de trabalho, mas, para o conjunto de sujeitos avaliados, não houve relação significativa. Isso pode ter ocorrido pela ausência de correlação ou por haver algum viés de confusão.

Houve relação significativa entre a utilização do pódio e piano e o aumento da prevalência de dor das regiões mais afetadas. Testes estatísticos demonstraram p-valores abaixo de 0,05* quando testada a relação entre uso do pódio e dor associada à regência em: ombro direito, ombro esquerdo, pescoço, região dorsal e região lombar. Os riscos associados a problemas com especificações de altura e instabilidade do pódio são ressaltados na literatura (Geraldo e Fiorini 2017; Averill e Sedatole 2011).

Também, houve relacionamento significativo entre o aumento dos relatos de impacto físico negativo e os participantes que atuavam apenas em conjuntos instrumentais. Também foi detectada uma prevalência relativamente maior nos relatos de dor entre os participantes que atuavam apenas em conjuntos instrumentais aos que atuavam em conjuntos vocais. No entanto, não foi possível verificar uma relação com significância estatística. É preciso que essa característica seja estudada de forma isolada.

Como a literatura indica que a manutenção da postura em pé é um fator relevante na atividade de regência, foi verificado o relacionamento entre as prevalências de dor nas regiões responsáveis pela postura. Houve relacionamento significativo, com p-valores* próximos a zero, nos testes entre as regiões pescoço, região dorsal, região lombar, joelhos, tornozelos e pés, duas a duas. Os testes indicam que os regentes relatam dores em, ao menos, duas dessas regiões.

O impacto vocal negativo é o terceiro mais relatado pelos participantes. Houve relacionamento significativo este aspecto e o tipo de conjunto em que os participantes atuavam. Os que regiam apenas conjuntos vocais relataram com mais frequência impacto vocal negativo. A literatura indica que os regentes corais têm demasiada exigência vocal, principalmente por conta do uso abusivo da voz falada e cantada, canto em regiões extremas da tessitura, posturas inadequadas e ainda pela atuação em atividades de cunho educacional (Gonçalves e Silvério 2009; Rehder e Behlau 2008; Macdonald 2004).

${ }^{3}$ Teste qui-quadrado de independência. 
Problemas com o impacto auditivo foram indicados por apenas $17 \%$ dos participantes. Desse aspecto com o tipo de conjunto em que os participantes atuavam, houve relacionamento significativo $\left(p-0,028^{*}\right)$. Os que atuavam apenas em conjuntos instrumentais relataram significativamente mais impacto auditivo negativo. Os conjuntos instrumentais têm, em geral, maior potência sonora. Ademais, há evidências na literatura de níveis de exposição acima dos recomendados para regentes de bandas escolares, por exemplo (Hayes 2013). A saúde do trabalhador define os limites no nível de ruído indicados para trabalhadores (Brasil 2015). 0 regente e demais músicos precisam adequar sua atividade de trabalho de forma a atender a essas especificações e a prevenir problemas por conta de uma exposição danosa (Lopes 2016).

\section{Conclusão}

Os resultados oferecem mais evidências de quais circunstâncias do trabalho de regência precisam de atenção dos profissionais para que adotem estratégias para afastar riscos ocupacionais. A similaridade com a literatura reforça que a postura, o movimento repetitivo e as condições ambientais são aspectos de impacto considerável na saúde do regente.

Os músicos e regentes precisam compreender que a exposição prolongada aos riscos ocupacionais pode trazer problemas que os afastarão da atividade de trabalho. Isso pode ter repercussão econômica significativa na vida dos profissionais. Logo, a prevenção parece ser um tema importante a ser desenvolvido. A conscientização dos indivíduos e das instituições musicais e de ensino, sobre aspectos de saúde, pode promover ambientes e rotinas mais saudáveis.

Concluindo, a deficiência na formação dos regentes quanto à falta de um enfoque mais profundo sobre questões de saúde também é um problema a ser enfrentado pelos pesquisadores e responsáveis pelo desenvolvimento dos currículos dos cursos formais.

\section{Referências}

Albuquerque, Flávia M. O. de, e Elirez Silva. 2003. "Saltos altos e artralgias nos membros inferiores e coluna lombar". Fisioter Brasil 5 (1): 18-21.

Averill, Jenn, e Kevin Sedatole. 2011. "Posture on the Podium: A Personal Trainer Assesses Conducting". The Instrumentalist 45: 26-29.

Brasil. 2015. Norma Regulamentadora de no 15 - Atividades e Operações Insalubres. Brasília: Ministério do Trabalho, Disponível em: http://trabalho.gov.br/seguranca-e-saude-notrabalho/normatizacao/normas-regulamentadoras/normaregulamentadora-n-15-atividades-eoperacoes-insalubres. Acesso em: 25-11-2018.

Costa, Cristina Porto. 2015. "Saúde do músico: percursos e contribuições ao tema no Brasil". Revista Opus 21 (3): 183-208.

Fortunato, Juliana G. S., Furtado, Monique de S., Hirabae, Leni F. de Assis, e Josiana Oliveira. 2013. "Escalas de dor no paciente crítico: uma revisão integrativa". Revista HUPE 12 (3): 110-117.

FUVEST. 2018. Fuvest 2019: Manual do Candidato. Fundação Universitária Para o Vestibular: São Paulo.

Gonçalves, Lilian S., e Kelly Silvério. A. 2009. "Aspectos vocais de regentes de corais adultos amadores". Anais do XIX Congresso da ANPPO, Curitiba, 66-69. 
Hayes, Patrick. 2013. "Noise Doses of High School Band Directors". Journal of Band Research 49 (1): 54-62.

Hryniewicz, Lygia, Gonçalves Costa, Vianna, e Maria Amorim. 2018. “Mulheres em posição de liderança: obstáculos e expectativas de gênero em cargos gerenciais". Cadernos EBAPE 16 (3): 331-344.

Jaque, S. Victoria., Karamanukyan, Isabel H., e Paula Thomson. 2015. "A Psychophysiological Case Study of Orchestra Conductors". Medical Problems of Performing Artists 30 (4).

Kella, John. 1991. "Medicine in the Service of Music; Health and Injury on the Podium". Journal of the Conductors Guild 12 (1-2).

Klickestein, Gerald. 2009. The Musician's Way: A Guide to Practice, Performance, and Wellness. Oxford: New York.

Lopes, Antonio Carlos. 2016. Tratado de Clínica Médica. Rio de Janeiro: Roca.

Rehder, Maria Inês Beltrami Cornacchioni, Behlau, e Mara Suzana. 2008. "Perfil vocal de regentes de coral do Estado de São Paulo". Revista CEFAC 10 (2): 206-217.

Rocha, Ricardo. 2004. Regência uma arte complexa: técnicas e reflexões sobre a direção de orquestras $e$ corais. Rio de Janeiro: Ibis Libris.

Sabioni, Cibele. 2016. "O perfil do regente que inicia coros comunitários no Brasil”. Anais do Simpósio Brasileiro de Pós-graduandos em Música, Rio de Janeiro 4(4).

VUNESP. 2018. Manual do Candidato: Vestibular 2018. Fundação Vunesp.

Watkins, John. 2007. The Art of the Conductor: The Definitive Guide to Music Conducting Skills, Terms, and Techniques. Lincoln: iUniverse Inc.

Williamon, Aaron. 2004. Musical Excellence: Strategies and Techniques to enhance performance. Oxford: New York. 